\title{
Health Technology Assessment and Ethics Health
}

\author{
Di Pietro ML and Zaçe D* \\ Department of Public Health, Università Cattolica del Sacro Cuore, Italy
}

Received: 制: September 21, 2018; Published: 制 October 01, 2018

*Corresponding author: Drieda Zaçe, Department of Public Health, "A Gemelli" School of Medicine, Università Cattolica del Sacro Cuore, Largo Francesco Vito 1, 00168 Rome, Italy

\begin{abstract}
A trend or a useful tool? HTA (Health Technology Assessment) was born in the 70s as a tool to support decision makers in the health sector and has been quickly developing since, also with the creation of specialized international agencies (e.g. Health Technology Assessment International - HTAi; International Network of Assessment Agencies of health technologies - INAHTA). What is HTA? It is the "systematic evaluation of the properties and effects of a health technology, which addresses the direct and expected effects of this technology, as well as its indirect and unintended consequences, and aims primarily to inform decision-makers on health technologies" [1].

The approach is interdisciplinary, because HTA summarizes information on medical, social, economic and ethical issues, and methods of evaluation can be different [2]. Since of its born, ethics has been considered a key element in HTA, even if there is still not an agreement on "why" and "how" ethics should be integrated in HTA. This difficulty is not new and it mainly due to the narrowing of HTA to economic analysis. In 2004, ten Have has listed some potential reasons of this situation:

a) Existing approaches for ethical inquiry are not suitable for HTA;

b) Technologies are often considered by HTA producers as being value-free;

c) The only questions perceived as relevant in an HTA are technical and economical ones;

d) Value issues may be acknowledged to be present at all levels in HTA, but ethics is not needed to address these issues;

e) It is practically difficult to integrate ethical considerations in HTA;

f) HTA experts are not trained to make ethical assessments and there is too little expertise on ethics and HTA; g. Limited resources available to conduct ethical analyses [3].
\end{abstract}

Abbreviations: HTA: Health Technology Assessment; HTAI: Health Technology Assessment International; INAHTA: International Network of Assessment Agencies of Health Technologies

\section{Current Debate on Ethics in HTA}

Why is ethics necessary in HTA? HTA represents a bridge between the scientific world (of research) and the political world (of decisions). When a decision must be made, we have to deal with questions that are not only qualitative (technical) but also quantitative (meaning and value). In technology, we can find answers regarding safety, effectiveness, efficiency and economic impact (quantitative questions), but not answers to ethical questions (qualitative questions). For example: Does the technology in question respect human's life? Does it improve the patient's quality of life? Is it accessible to everyone in the health system?

If ethics evaluation is central in a HTA, how can it be integrated in this process? According to some authors, this integration is not easy because of the epistemological difference between ethical domain and other domains of HTA [4]. In fact, an ethical analysis does not produce scientific evidence but uses the evidence reported by the other disciplines to highlight the moral issues and make an evaluation. Hofmann et al. identify four ways of integration:

a) Submission (ethics assessment is a subsidiary activity, a sub-project of an HTA);

b) Combination (ethics assessment is a separate activity);

c) Coordination (ethics assessment is a separate part or process in HTA, but its role and importance may vary depending on the context);

d) Interaction (ethics assessment influences, is influenced by, re-defines and is re-defined by other parts and elements of HTA) [5]. 
Other authors believe that it is not possible to separate ethics from a human choice. In fact, every free and voluntary act involves a moral question (licit / illicit, good / bad). As a result, ethics cannot be "integrated" into HTA because ethics is already a constitutive part of HTA. However, ethics can be recognized and emphasized [6]. The issue is not the expansion of HTA, to include ethics or integrate ethics into HTA [7], but to acknowledge that the use of any health technology will inevitably raise questions of meaning and value. HTA's mission is to maximize population's health and influence decision-making, taking into account and promoting equity and values and therefore also all the value judgments involved in the evaluations [8]. Therefore, it becomes necessary define the ethical approach in HTA assessment. Unlike the other fields of an HTA process, which are based on standardized methods of analysis, the ethical analysis is influenced by the ethical choice and the method of analysis.

There are different methods, theories and positions that can be used to analyse ethical problems in HTA (e.g. Utilitarianism, Deontology, Casuistry, Principlism, Discourse Ethics, Wide Reflective Equilibrium) [9-11]. In addition to this, some ethics approaches, and methods have been developed and used especially for HTA (e.g. Socratic Approach; Social Shaping of Technology; Constructive Technology Assessment; Ethical Matrix; Interactive Health Technology Assessment) [5]. Furthermore, ethical analysis can be conducted in a descriptive or normative way. The descriptive way provides a list of ethical issues, which have to be identified, described and addressed (the most used modality); the normative way provides a moral judgment (e.g., the use of a technology is morally good/bad or ethically licit illicit) [12].

\section{As a Proposal}

Among normative models, our School uses the Triangular model [13]. The Triangular model, also known as the "personalist model", is rooted on the human person (body-soul unitotality) as reference-value in the reality, according the Aristotelian-Thomistic view. This approach includes factual, anthropological and ethical data in a "triangular" normative reflection process. The three steps of ethical process are:

a) Data collection (knowledge level): an in-depth study of factual data concerning the object of the analysis;

b) Ethical/anthropological analysis (justifying level) according to the following principles criteria:

i. The defense of human physical life;

ii. The therapeutic principle, according to which the human person has to be treated as a totality of body and soul; iii. The interconnection between personal freedom and responsibility;

iv. The principles of sociality and subsidiarity, for which public/ private bodies are called to help all persons, namely when they are not able to fulfil their needs;

c) Appraisal (normative) level, that should establish if implementing a certain technology is ethically licit/illicit, and, therefore, facilitate practical choices [14].

\section{References}

1. HTA glossary (2018) International Network of Agencies for Health Technology Assessment.

2. https://www.eunethta.eu/.

3. Ten Have H (2004) Ethical perspectives on health technology assessment. Int Technol Assess Health Care 20(1): 71-76.

4. Refolo P, Sacchini S, Brereton L, Gerhardus A, Hofmann B, et al. (2016) Why is it so difficult to integrate ethics in Health Technology Assessment (HTA)? The epistemological viewpoint. Eur Rev Med Pharmacol Sci 20(20): 4202-4208.

5. Hofmann B, Oortwijn W, Bakke Lysdahl K, Bakke Lysdahl K, Refolo P, et al. (2015) Integrating ethics in health technology assessment: many ways to Rome. Int J Technol Assess Health Care 31(3): 131-137.

6. Hofmann BM (2008) Why ethics should be part of health technology assessment. Int J Technol Assess Health Care 24(4): 423-429.

7. Daniels N, Porteny T, Urritia J (2016) Expanded HTA: Enhancing Fairness and Legitimacy. Int J Health Policy Manag 5(1): 1-3.

8. Abrishami P, Oortwijn W, Hofmann B (2017) Ethics in HTA: Examining the Need for Expansion. Int J Health Policy Manag 6(10): 551-553.

9. Van Der Wilt GJ, Reuzel R, Banta HD (2000) The ethics of assessing health technologies. Theor Med Bioeth 21(1): 103-115.

10. Sacchini D, Virdis A, Refolo P, Pennacchini M, De Paula IC (2009) Health technology assessment (HTA): Ethical aspects. Med Health Care Philos 12(4): 453-457.

11. Assasi N, Schwartz L, Tarride JE, Campbell K, Goeree R (2014) Methodological guidance documents for evaluation of ethical considerations in health technology assessment: a systematic review. Expert Rev Pharmacoecon Outcomes Res 14(2): 203-220.

12. Sacchini D, Refolo P, Minacori R, Spagnolo, Antonio Gioacchino (2016) The ethical domain in Health Technology Assessment (HTA): basics, approaches and issues. Rivista Internazionale di Scienze Sociali 3(4): 385-396.

13. Sgreccia E (2013) Human person and personalism. Cuad Bioet 24(80): 115-123.

14. Di Pietro ML, Teleman AA, Gonzalez Melado FJ, Zace D, Di Raimo FR, et al. (2018) Implementing carrier screening for cystic fibrosis outside the clinic: ethical analysis in the light of the personalist view. Clin Ter 169(2): 71-76. 
ISSN: 2574-1241

DOI: 10.26717/BJSTR.2018.09.001807

Drieda Zaçe. Biomed J Sci \& Tech Res

(c) (i) This work is licensed under Creative

Submission Link: https://biomedres.us/submit-manuscript.php

Assets of Publishing with us
RESEARCHES $\quad \begin{aligned} & \text { Global archiving of articles } \\ & \text { - Immediate, unrestricted online access } \\ & \text { - Rigorous Peer Review Process }\end{aligned}$

